\section{Old tasks given a new life}

\section{Paris}

"If we work for the poor and the penguins simultaneously, we can hope for a better common present and future", says Professor M. Swaminathan, President of the Indian National Academy of Sciences. His poetic statement gives the gist of a meeting at UNESCO, the United Nations Educational, Scientific and Cultural Organisation, last week*, involving about 90 scientists and heads of multilateral science and technology organizations.

The meeting followed another Paris colloquium on global environment issues, "Planète Terre" (see right), and several participants attended both meetings - not a coincidence, according to a UNESCO spokesman, but "smart timing". UNESCO's aim, said director-general Federico Mayor, was to encourage "the international community as a whole to take a fresh look at the status of cooperation in science and technology on the eve of the closing decade of this century."

At the end of August, the United Nations Intergovernmental Committee on Science and Technology for Development (UNCSTD) will meet in New York to evaluate progress since its meeting in Vienna in 1979. But, Mayor emphasized, the Paris meeting was not intended to upstage that end-of-decade review, simply to "spark off new dialogue".

Many of the participants agreed that actions proposed in 1979 have failed to materialize. "There was total agreement at UNCSTD", according to Dr M. G. K. Menon, president of the International Council of Scientific Unions, "but there was no follow-up, there was no implementation, there was no adherence by nations to the decisions they were party to."

This, said Sergio Trindade, Assistant secretary-general of UNCSTD, had come about because priorities have been mixed; one result has been that organizations have been supported, but goals have not been set. Faced with the "sclerosis" of the Vienna proposals, Menon says the need now is for a "collateral bypass operation" to strengthen endogenous science in developing nations, while creating better international collaboration.

Many agreed that UNESCO, the only United Nations organization specifically concerned with science and technology as well as education, would be ideally suited to perform this 'operation'. But this is unrealistic so long as Britain and the United States continue to refuse to rejoin.

According to F. Sagasti of the World Bank and chairman of the UN advisory committee for the application of science and technology to development, all of the

* The High-Level Colloquium on Science and Technology for the Future: A Fresh Look at International Cooperation in Science and Technology. istry and for earth sciences. UNESCO. multilateral organizations need to be reshaped. They were set up "in the shadow of East-West conflict", he says, whereas the present and future dialogue must be between north and south.

But Professor Roald Sagdeev of the Soviet Academy of Sciences felt that technology cooperation between East and West still has far to go. When the University of Chicago sent an experiment aboard the Soviet probe in the encounter with Comet Halley in 1986, a 'black box' of Radio Shack components was used to overcome COCOM regulations on technology transfer to Eastern bloc countries.

The main obstacle to north-south collaboration is the widening rift between the 1.1 billion haves and the 3.6 billion have-nots, said Professor Abdus Salam, director of the International Centre for Theoretical Physics (ICTP) and President of the Third World Academy. Developing countries still see basic science as a luxury and, as a result, lack the trained teachers, engineers and scientists to collaborate. Salam argued that more institutes on the lines of ICTP are needed and has launched an appeal to create three new international centres - for high technology and new materials, for pure and applied chem-

The conference lacked neither realism nor optimism in its analysis of the future of science and technology for development. Much now hangs on the outcome of the UNCSTD meeting and, eventually, on the return of the United States and Britain to

Peter Coles

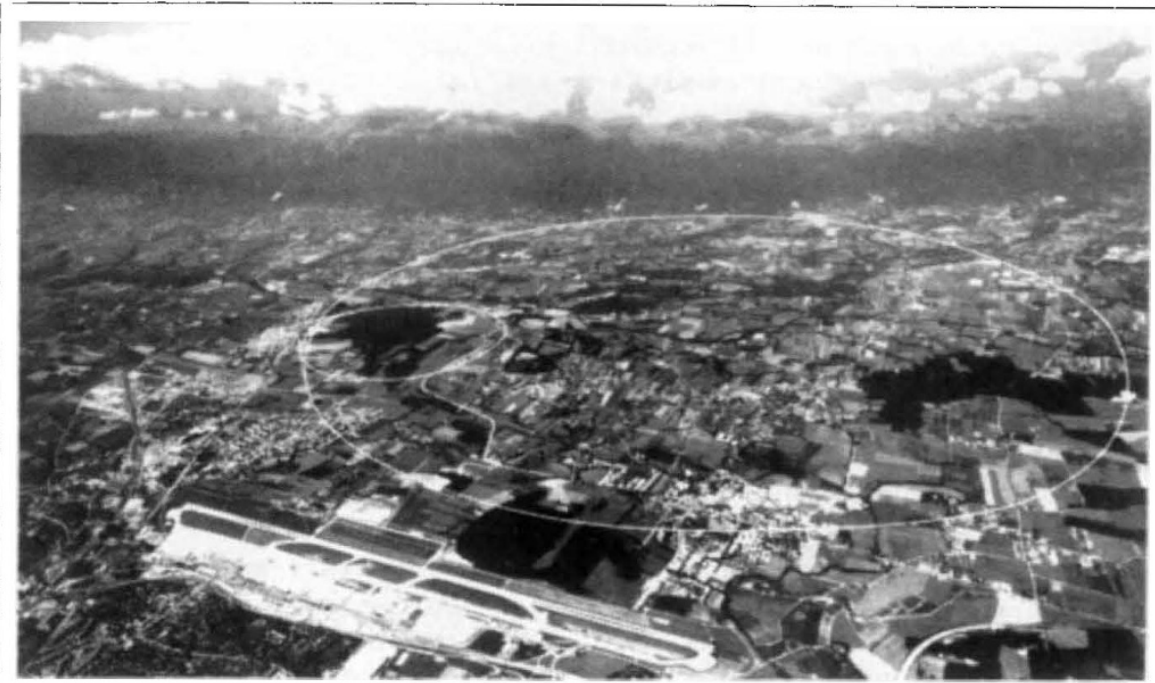

THE completion of the large electron-positron collider (LEP) was announced last week by CERN, the European laboratory for particle physics. The circular machine, housed in a $27-\mathrm{km}$-long tunnel between 50 and $150 \mathrm{~m}$ below the surface, accelerates electrons and positrons to a combined energy of $200 \mathrm{GeV}$. LEP's main purpose is to investigate the $Z^{0}$ particle, discovered at CERN, and although the Stanford linear collider recently made its first $Z^{0}$ (Nature 338, 606; 20 April 1989), LEP has more than two times the beam energy of its rival and is expected to generate $Z^{0} s$ at a higher rate. LEP is the result of an eight-year project financed by the 14 member states comprising CERN. 